\title{
Multimedia in construction education: new dimensions
}

\author{
Mark Shelbourn ${ }^{1}$, Ghassan Aouad ${ }^{1}$, Mike Hoxley ${ }^{2}$ \\ 1 Research Centre for the Built \& Human Environment, The University of Salford, \\ Salford, M7 9NU, UK \\ 2 Division of Property \& Construction Management, Business School, Staffordshire \\ University, Stoke-on-Trent, ST4 2DF, UK \\ email: m.a.shelbourn@surveying.salford.ac.uk
}

\begin{abstract}
The use of multimedia for educational purposes has generated considerable discussion in recent years. This paper discusses a number of different ways in which multimedia can be used in the construction industry. Learning from other industries, particularly manufacturing is essential as multimedia has been explored and exploited by such industries. The first half of the paper demonstrates how multimedia can be used to aid learning and training in the construction sector and in disseminating research results to an industrial audience. The second part demonstrates how multimedia can be used as an interface to complex integrated database systems using virtual reality technologies. These can be used in a laboratory environment to train industrialists and students to use integrated systems, a topic of great importance and traditionally known to be difficult to understand. The work presented here builds upon research undertaken at the University of Salford in the UK through the use of case studies and findings generated from workshops attended by industrial collaborators who are interested in improving the ways in which information is delivered in the construction sector through multimedia capabilities.
\end{abstract}

Keywords: Multimedia, Learning, Virtual Reality, VRML, Project Information, Education

\section{Introduction}

Many construction professionals have realised the importance of multimedia and are starting to incorporate it into their everyday work within the AEC (Architecture, Engineering and Construction) industry. Multimedia was viewed with scepticism when it was first 
introduced but now it can be found in many practices and offices. Multimedia is a term used to describe computer programs that combine multiple mediums including graphics, text, video, animation, and sound. Although there are some programs that contain all of these elements, a program containing only a few is still considered to be multimedia. Multimedia has been widely used by other industries, particularly manufacturing. This paper reviews the work done in this area and captures best practices that can be transferred to construction. In addition, this paper presents the main findings of various construction research projects conducted at the University of Salford in the UK within the multimedia domain and within an education context. The areas covered in this paper include computer-aided-learning and research dissemination, and computer aided interfacing using multimedia. The research methodology used for the research is based on case studies and scenarios developed through industrial workshops (every workshop is held quarterly and attended by 10-15 industrialists representing the supply chain in construction).

\section{Multimedia in Manufacturing}

The manufacturing industry has used computers to improve its processes and productivity far longer than construction. It would seem logical that the construction industry can learn from manufacturing. In 1986, General Motors started to develop "simultaneous engineers"[1]- engineers who are given the responsibility of both designing and manufacturing the car. The experiment with simultaneous engineers was aimed at reducing the five-year lead-time needed to bring a car to market and improving the overall quality of the automotive products.

The problem preventing computer-integrated-manufacturing, as described by Merchant in 1987 [2], is that the databases and knowledge associated with design and that of manufacturing are quite different and, for the most part, not overlapping. The manufacturing industry is attempting to better integrate the design and manufacturing components in two basic ways:

1. By developing computer architectures that allow common access amongst all the users of the information and models, using multimedia technology; and

2. By realigning organisations and traditional job assignments to encourage broader involvement and understanding of product development and manufacturing, i.e., simultaneous engineering. [1]

Merchant's approach is clearly appropriate to the construction industry as well as that of manufacturing. Good progress has been made in the automation of some design construction 
activities in the office and on-site. However, it is the integration of these activities that has been lacking in the construction industry. Multimedia will aid in the better understanding of how this can occur.

There is an important difference between construction and manufacturing that suggests that well-developed computer architectures may even be more important for the integration of construction activities than manufacturing. In manufacturing the procurement process is well managed. The plant manager can dictate organisational and job changes that augment and encourage the desired integration. The trend is towards just in time (JIT) manufacturing which is resulting in tighter integration between the manufacturer, suppliers and subcontractors. By contrast, in the construction industry, architectural, engineering, fabrication, construction, and facilities management activities are often distinct economic units with different objectives and long-term business policies. As such, organisationally driven integration of these functions cannot be so easily realised. Therefore, a uniform information architecture is more important in construction than manufacturing.

A special issue of the research journal "Computers in Industry" highlights the growing trend of using multimedia in the manufacturing industry. [3] The issue contains some interesting processes and techniques that could be adopted by the construction industry. There is a comprehensive review of the current status of multimedia in manufacturing. In this issue, a paper on the "Virtual Workbench" [4] which is a technique applied to manufacturing that could quite easily be adopted by the construction industry is described. The user wears a virtual reality helmet that he/she uses to look at a workbench. The workbench displays designs of industrial products and how they can be manufactured. This principle could be used by architects to show their clients and other members of the project team the processes needed to construct their design. The paper by Huang \& Mak [5] uses many of the principles of the OSCON system described later in this paper. The paper by Crowder et al [6] has similar principles to those used in the designing of the BRIEFING program also described later in the paper. The examples given above show how the construction industry is starting to use manufacturing processes and techniques in multimedia to develop programs that aim to make the construction industry more technology friendly to its members.

Although some similarities exist in philosophy between computer-integrated manufacturing and computer-integrated construction, the differences that exist among these two program domains in considerations such as scale, process technology, safety, human factors, cost, sensors, communication and information technology, hardware capabilities, realtime / on-line control requirements, technology integration and reliability lead to 
fundamentally new and multi-disciplinary areas for research. Multimedia technology will undoubtedly play a significant role in undertaking this research. The design and implementation of multimedia programs has become much easier with developments in authoring software, and the introduction of the WWW means that results can now reach a much wider audience.

\section{Multimedia in the AEC Industry}

The introduction of both "Passive" multimedia, (multimedia used to portray a sequential presentation) and "Interactive" multimedia (enables the user to select their own course through the information) has heralded a new era for the AEC industry. Multimedia has been widely used in the Civil Engineering and Construction Engineering fields. In this section some programs developed within the AEC industry are outlined. Programs in the planning and design phases of a construction project life cycle have included architectural and structural programs that show animated walk throughs of prospective buildings. In 1994 Vanegas \& Baker [7] used multimedia to portray a comprehensive design and bidding documenting system. It gave details to contractors on the most appropriate way of successfully tendering for a particular contract. In 1994 McCullouch \& Patty [8] used multimedia in a program that enabled the users to review and learn lessons from mistakes made in the construction of roads and highways.

In 1998 Saad \& Hancher [9] took the principles of documenting results; failures or any other project information further by designing a multimedia program called "Project Navigator." The program displays the flow of information within the different phases of a construction project, the management tools used to display this information, and the feedback gained from the phases of the project. The information is stored within a central multimedia library. The program was targeted for use at any person participating in a construction project, and members of academia. In 1996 El-Bibany [10] used multimedia as an object oriented interface-based simulation. The program was based upon earthmoving machinery; in particular machinery called "scrapers". The main objectives of the project were to show the different parts of the scraper, explain how they work, describe the different types, discuss the variables which influence productivity, explain the analytical and graphical methods for optimising the scraper's production, and give the user some experience of the techniques needed in equipment operations management. The objectives were achieved by showing the user a specific type of scraper on a video, with the scraper's load-growth being plotted on a graph next to it. The student can experiment with the load-growth characteristics in the graph 
with the results being shown in the video.

In 1997 Howard [11] reported how multimedia can be used to link expert's views to derive common conclusions in a format that can be produced electronically. The advantage of this resource is that reports such as "Building IT 2005" can be accessed by a wider audience to gain specific information on the subject they are interested in. The information contained in the CD-ROM version of "Building IT 2005" can then be linked to the original journal article, conference proceedings or report using the WWW as a means of accessing this original data. The use of multimedia and the WWW means that the amount of information available to the user is much larger and at their fingertips, rather than searching in libraries and stores.

The design phase of the project life cycle has used computer software to show off the designs of buildings for some years. The introduction of improved technology means that these designs can now be integrated into more complex systems. Work undertaken by Stanford University in 1998 in collaboration with Mitsubishi heavy industries developed BERT, “...conceptual design systems in Building, Engineering, and Reasoning Tool,”[12] which is a decision-support tool for the designs of moment-resisting steel frame structures. Developing tools to aid the planning and management of projects has also increased. Examples of this include DISCO, (dynamic interface simulation for construction operation) at Purdue University (USA), RUBICON at Carnegie-Mellon University (USA), COOPS-R at Ann Arbor at the University of Michigan (USA), and PRISM, (Project Representing Intelligent Site Modeller) in Japan [13] where 1998 Papamicheal et al. have used multimedia as an interface in a program that uses multiple systems and visualisation tools in the building design process, called "Building Design Advisor". The program uses an object-oriented representation of the building and its context, and acts as a data manager and process controller to allow designers to gain the benefits of the multimedia interface. The program consists of two main features, the Building Browser, which allows the designers to quickly sort through the information addressed by the visualisation and analysis tools, and the Decision Desktop, which allows the designers to develop many designs with respect to multiple parameters gained from the Building Browser. This information is then passed to the Schematic Graphic Editor (SGE) which allows the designers to specify the geometric aspects of building components. The SGE also has a daylight analysis tool, an energy analysis tool, and a web based Case Studies Database tool integrated into it.

At the University of Wisconsin-Madison a number of research projects have shown how multimedia can be used as an interface to systems that contribute to the AEC industry. [12] A computer-numerically-controlled pumped-concrete placement program has been developed to 
aid efficient path plan design for the pouring of concrete during construction of commercial properties. The system consists of a path planning module, a motion control module, and a pumping pressure control module. The plans of buildings contained in CAD are utilised to determine where the concrete should and should not be poured. The motion control module verifies the speed at which the pipe needs to travel along the chosen path, and how fast the controllers of the boom/pipe should move. The decisions of the motion controller are determined in real time at the site as they depend upon the number of workers needed for the compaction and screeding processes. This information is not available in the office where the paths of the concrete pouring are determined. These types of program are examples of how computers can benefit the industry to improve quality, cost, safety and productivity. The pathplanning module of the concrete project has been utilised in another project for designing paths for compacting asphalt pathways. The system estimates how many passes a roller should take to ensure the asphalt pathway has been adequately compacted to maximise its performance.

\section{Multimedia in Education}

Computers have been used in education from a surprisingly early stage. The first Computer-Aided-Learning (CAL) program was developed in 1954, although, it was not until 1966 when Patrick Suppes [14] predicted that it would "...change the face of education in a very short time...", that it became more prominent. With technical advances in personal computer design in the 1980's it became more practical to develop CAL programs. By 1985, $80 \%$ of secondary schools and $95 \%$ of primary schools had some level of computing. [15]

It is widely acknowledged that Computer Aided / Assisted Learning (CAL) systems aim to provide learners with both a rich set of learning resources and tools to help them navigate through stimulating learning scenarios. The advent of high quality graphics and multimedia has heralded an increased research effort in this area. Learning styles that were previously impractical are now being developed and supported by state of the art CAL systems. The following quotes briefly capture what multimedia can achieve:

"...I hate the idea that novels are not interactive. I've got 26 symbols and a handful of punctuation and I can create in your mind sounds and visions and people and scenery - and all this is specific to each individual..." [16] and,

"...our experience of life is multi-sensory...so multimedia is a highly appropriate way of presenting it" [17] 
There have been many arguments about the usefulness of multimedia in education and whether its implementation is actually worth the expense and extra training that would accompany its introduction into education on a larger scale. Ion and O'Donnell [18] have demonstrated this in the Department of Design, Manufacture, and Engineering Management, at the University of Strathclyde in the UK. In trying to implement CAL they have shown that the issues of the "likely economic and educational benefits, the availability and use of CAL material, and implications on resources" have to be considered. They concluded that:

"...CAL in its many forms will become an integral part of teaching in much the same way as other aids such as the overhead projector have in the past." [18]

Multimedia is not the only answer to education and learning, but if properly implemented it can certainly help. [19]

CAL can be a particularly powerful tool for distance learning. The Rochester Institute of Technology combines videotape, CAL tutorials, on-line classes and printing facilities to their distance learners. Such media mixes are bound to become prevalent in the near future and many academics predict a huge rise in video-conferencing in higher education. Computers can revolutionise distance learning, [20] particularly the on-line systems. Multimedia has great potential, along with the World-Wide-Web, (WWW), to be interactive and thus develop learning through both discovery and exploration of the new technology available on the market today. This also underlines another feature associated with distance learning. In 1984 work undertaken by Tait \& Hughes [21] showed that "self teaching and assessment" would become much easier with the introduction of Computer Based Learning Systems, (CBL's). The work concluded that the use of multimedia for these activities would significantly improve the learner's performance.

\section{Using Multimedia as a Form of Disseminating Research Information}

As part of a Engineering and Physical Sciences Research Council (EPSRC) project to improve Briefing Practices in Construction, Barrett and Stanley [22] have used the "Asymetrix Multimedia Toolbook" (MTB) authoring system. This is one of the best-known multimedia software production environments for the Windows platform. There are other software products on the market that could have been used. Butters \& Corke [23] used some of them in a multimedia CD-ROM project at Liverpool John Moores University in the UK. MTB is particularly well suited to large multimedia projects because it is based on a structured programming model, providing features that make it easy to break down a large project into modules so that different parts can be assigned to different teams. Tait [24] who 
used the Toolbook software on a large-scale multimedia project has shown this. The project was similar in size to the Briefing program. MTB provides a very powerful prototyping environment, and is simple enough for inexperienced programmers to learn to use while other features included make it fully extendible for even the most demanding applications.

Within this project the Toolbook system was used to provide an alternative method of disseminating information to the traditional written report. A multimedia CD-ROM was produced as well as a book, with the CD-ROM being able to provide much more information due to its ability to portray, store and display information in a more user-friendlier format.

The interactive nature of the program means that the users become responsible for their own learning, interacting with the material as opposed to passively receiving the information. The interest of the user is thus maintained throughout since they are forced to make choices and are provided with feedback as to decisions made ensuring misconceptions and user problems are answered immediately. This type of learning was demonstrated by Akpinar \& Hartley [25] in research where they concluded that keeping the users interest in the material contained in any CAL program is the most challenging aspect to designing the CAL program.

The Briefing CD program was developed using the prototyping methodology. Information from the project was passed to the developer with instructions on how to present it. The developer then portrayed the information using the MTB software. Feedback was given back to the developer from other members of the project team, with any changes being made to the pages as necessary. Regular meetings were held with the industrial partners and sponsors to discuss the progress of the project. During these meetings the parties were shown the latest version of the program. Feedback from the partners and sponsors gave insight as to the user requirements that they felt were important for the program to succeed. These requirements were then built into the program to make it as user friendly as possible. This process continued until the program was practically completed. In order to test the program the application was sent out to the industrial partners and sponsors to test it on their systems. Feedback from these tests was recorded and changes made until the program was completed and ready for final distribution.

The benefits of multimedia courseware have been outlined above, but it is important to reinforce the disadvantages of Computer-Aided-Learning based teaching, i.e., the significant costs of hardware, software and maintenance, administrative problems, the perceived threat to jobs and health issues such as VDU exposure.

\section{Using Virtual Reality as a Multimedia Tool to Train Inexperienced Surveyors in}




\section{Building Pathology}

Building Pathology is a term that simply means identifying faults / defects in buildings. It has been difficult to train young inexperienced surveyors in this practice due to insurance and logistical problems of enabling a large group of students to visit a property where defects can be found. Many employers of young surveyors in the UK are now recruiting surveyors directly from higher education rather than traditional apprentice type applications. To overcome these problems a project is being developed, [26] that enables young and inexperienced surveyors to gain skills in diagnosing defects in buildings without leaving the confines of a computer desk. The project incorporates a number of different fields of expertise that are outlined below.

There has been a significant increase in professional indemnity insurance claims in the last 15-20 years and the main insurers have incurred significant losses in insuring surveyors during this period. There have been a number of high profile cases of low levels of competence and poor levels of service provided by surveyors to their clients. The most recent "attack" on the surveying profession in the UK was a National TV documentary [27]. The TV programme researchers set up an experiment with 10 surveyors engaged to carry out a Homebuyers Survey of a property that had several defects. The general standard of the reports prepared by the majority of the surveyors was adjudged to be poor.

The use of Virtual-Reality in this project is very important as it gives the user a visual portrayal of a defect in a building. The findings of a study by Brna [28] concluded that using VR environments in this manner is more beneficial to the learner than more traditional "chalk-and-talk" methods of teaching. A typical $19^{\text {th }}$ century property is being used for the model - almost half of the UK housing stock was built before 1945 [29]. The virtual environment is produced using the "Superscape - VRT" software.

The environment will show the property with many programmed defects hidden, which the user has to identify. The application is designed as a CAL application. The defects are taken from real-life examples obtained from collaboration with local surveying practices. The defects are photographed with a digital camera so that they are in a format that can be easily recognised by the VR software. This reduces problems of scanning the photographs where the quality of the picture can be reduced. The VR environment forms the main basis of the application, as this is the main view that the user has of the application.

A Case-Based-Reasoning program has been developed to provide the different defects to be portrayed within the VR environment. Each individual defect is stored as a separate case within the software and as each user uses the application different defects can be portrayed in 
the VR environment.

This particular approach has been used on another CAL application within the University of Salford. A CAL application was developed using VR as the interface to identify whether or not different scaffolding of a property complied with current statutory requirements. [30] Each individual scaffold was saved as a single case. When the application was loaded a new type of scaffold was portrayed within the VR environment for users to comment upon to see whether or not it does comply with current statutory requirements. Some of the application's fundamental designs have been incorporated into the building pathology application.

Figure 1 below is a schematic diagram of how the system is designed and implemented. It shows the different types of software that are to be used and how they are linked together.

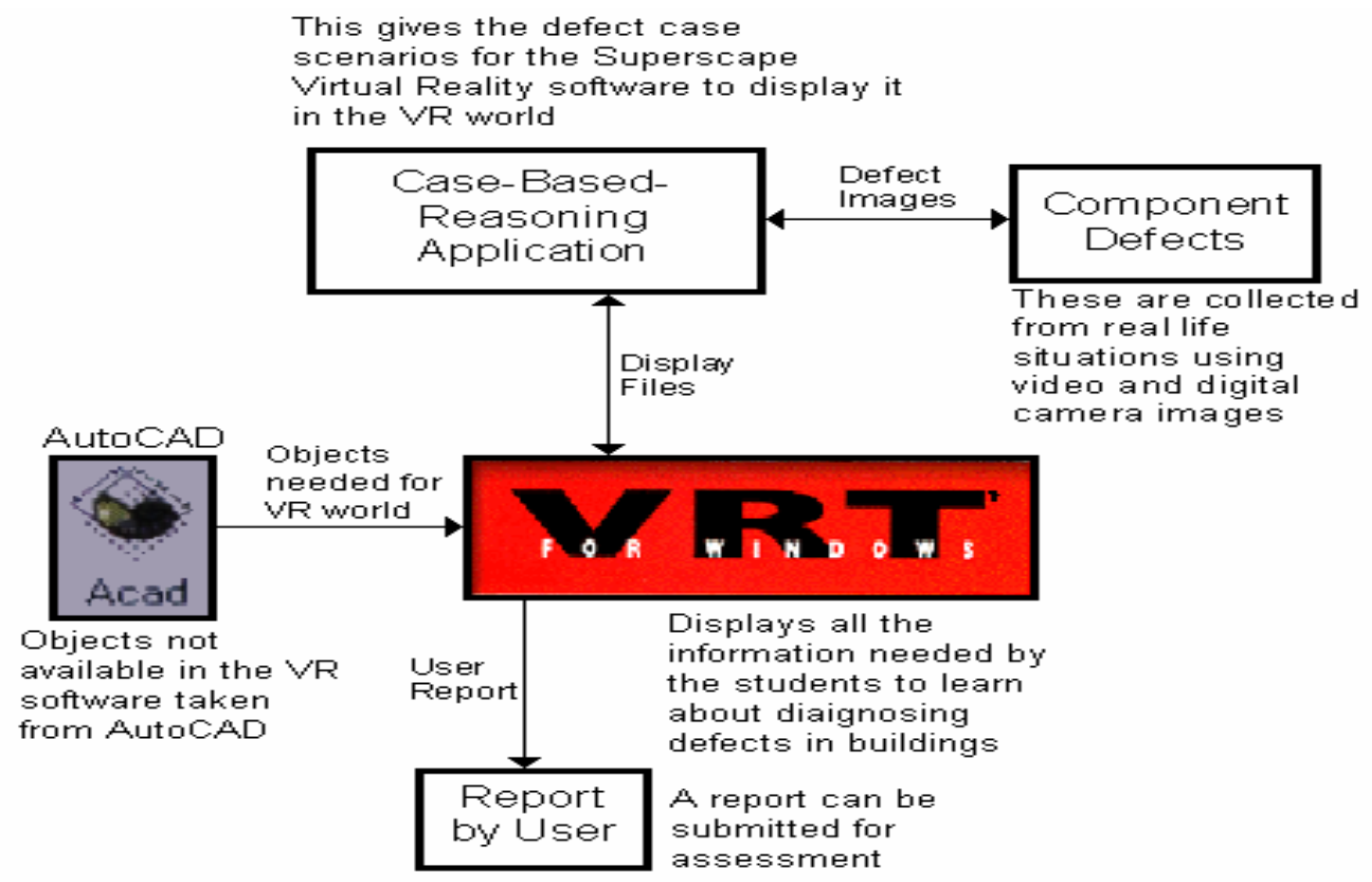

Figure 1 Diagram showing the programs design \& implementation [26]

\section{Using Multimedia as an Interface for Complex Systems}

Research undertaken by Marir et al [31] has shown how multimedia technology can be used as an interface to a complex system. The system is called "OSCON". (Open Systems for CONstruction) The system was developed using a VRML (Virtual Reality Modelling Language) interface to an integrated object oriented database, which supports the design, planning and estimating of buildings. The database uses the Object Store software, from which the information can be retrieved and stored. The user can interact with a Virtual Reality 
(VR) model without having to understand the background programming of the system. The user queries the database using the VR model to obtain information on elements of a proposed design of a building. Information available to the user includes texture, cost and time of elements within the building. As VRML is a World-Wide-Web (WWW) programming standard the information can be passed to other construction professionals relatively easily using the Internet. The traditional user interface for querying databases has proven to be problematic. One solution is to browse the information using a Virtual Reality interface. The VR interface is a more natural way of browsing the information as the user can visually identify the objects and retrieve them using the VR interface. The OSCON team adopted this particular approach. Within OSCON the user navigates through the VR model and identifies elements of interest by clicking on them. Information about the object selected is retrieved from the database depending upon the view or the requirements of the user. Different information can be obtained from the database for different construction professionals. An example of this is that a designer can retrieve information about a specification for a cavity wall, a Quantity Surveyor can obtain information about the cost of the wall, and the time planner queries the model to retrieve information about the time it takes to build the wall. [31] 

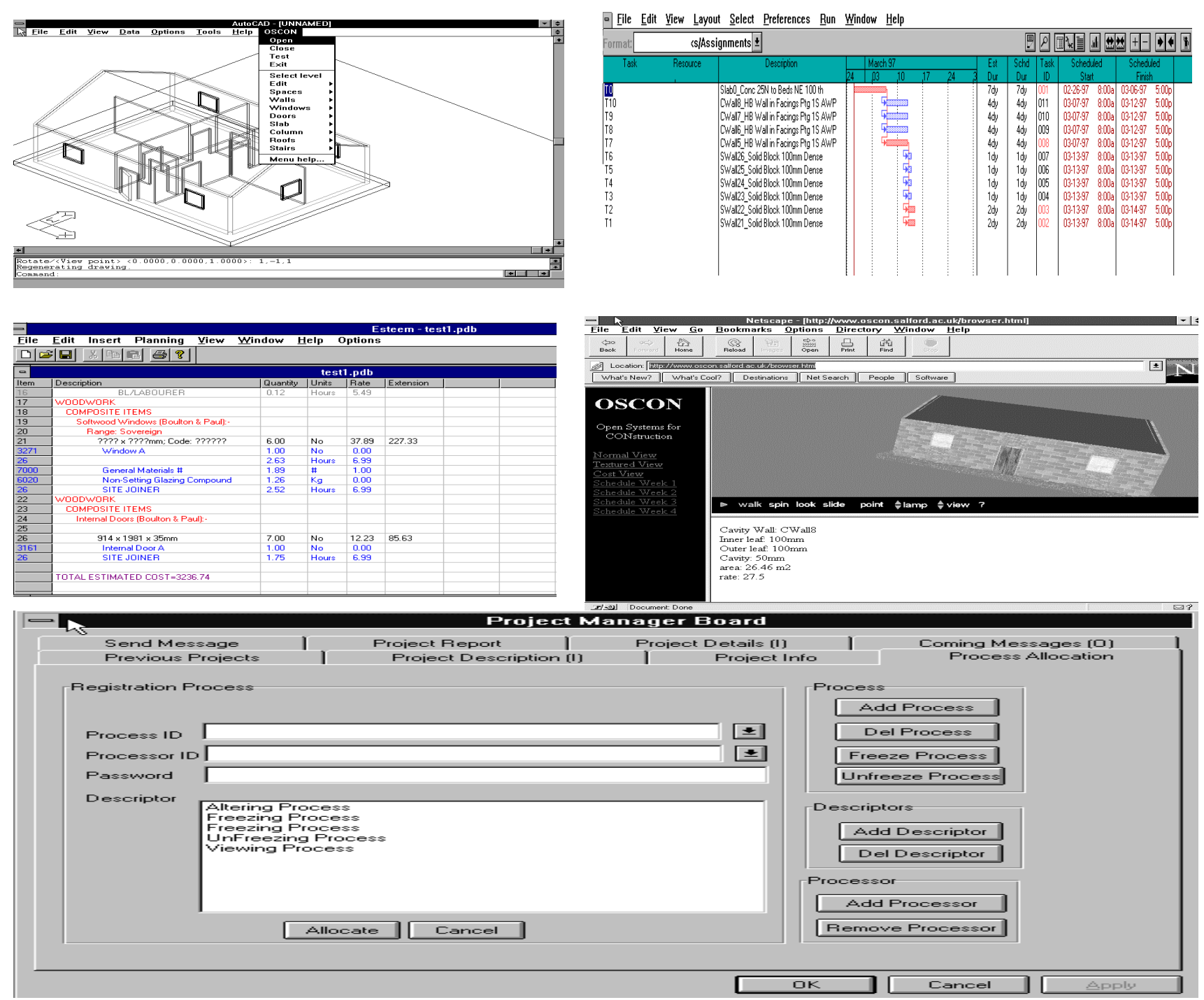

Figure 2 The OSCON integrated applications

Figure 2 shows graphically the various applications that are linked together. The VR application retrieves the information about the design produced in AutoCAD from the database and reproduces it in the VR environment. Visualisation is improved using the webbased VRML programming language. The OSCON integrated database is queried over the Internet in order to allow different practitioners to obtain information. The advantages of using the WWW and VR as an interface have never really been explored. The ease of access and real-time integration can easily be achieved. VRML allows the creation of 3-Dimensional views and worlds, which can be explored in real time. With the use of the Internet the system can be fully exploited to portray construction information to many professionals in many geographical locations.

VRML is an ever-changing standard describing interactive three-dimensional scenes 
developed across the Internet [32]. A VRML browser is required to load VRML files which allow the users to navigate through VRML worlds. The VRML file is a text file that describes the VRML world. It contains nodes that describe shapes and their properties. The four primitive shapes are cube, sphere, cone and cylinder.

Figure 3 shows the link between the VRML viewer and the integrated database and shows how information is retrieved from the database.

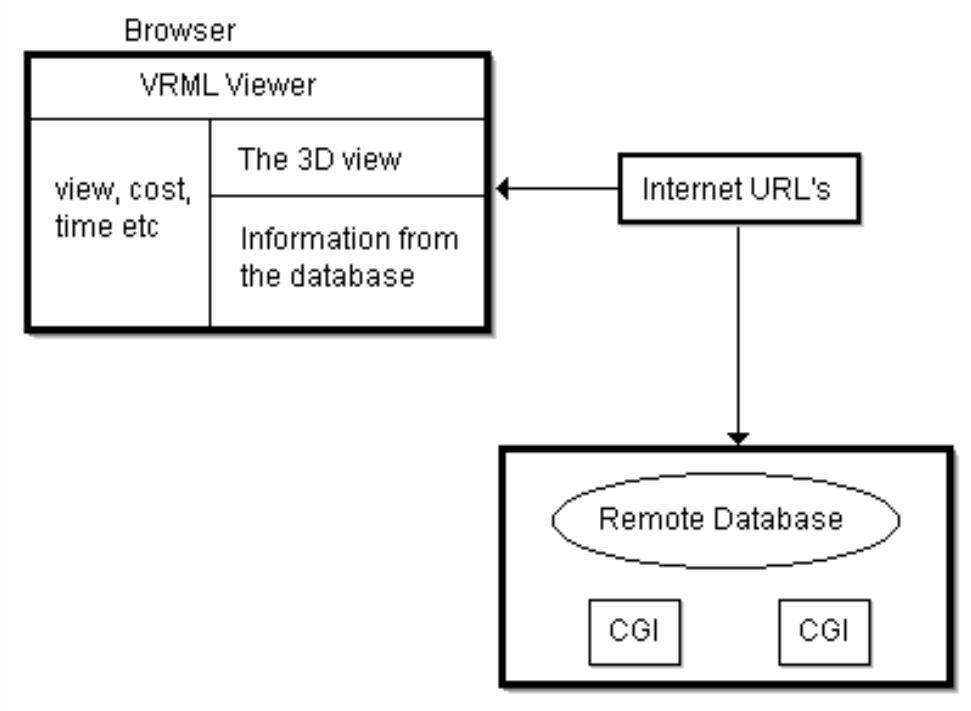

Figure 3 Diagram showing the link between a VRML viewer \& the integrated database

The VRML standard allows different users to view worlds and link them together over the Internet. When a user clicks any anchored object they request information from other worlds using a URL (Universal Resource Locator) that gives the address of the required file on the web. Worlds obtained from the Internet are delivered by the web server running on a remote host at a remote Internet site. In this case, the URL specifies a CGI script, which is a C++ program that runs on the remote host under the direction of the web server. The CGI program returns information about the objects being queried in the VRML browser. [31]

The system described here is relatively complex but the use of VRML as a multimedia means has facilitated the retrieval of information. Universities and industrial organisations in generating better understanding of integrated databases can use this system to train their students and employees. The system can be used as an example to students attending tutorials learning about integrated systems. The framework of the system allows an expert in integrated systems to describe how the system is put together and how other automated programs can be easily integrated into it. As the system is web based it is an ideal tool for distance learners to 
view and use as a case study in their studies. The system is being used at Salford as a teaching tool. It has been demonstrated to many academics and industrialists and the majority favour its use for teaching and education purposes. VRML is an appropriate environment for teaching purposes and as it is web-based, this will assist many users to be trained remotely.

\section{Conclusions}

This paper has discussed how the use of multimedia can enhance education. It has highlighted the advantages of using information technology and in particular multimedia to produce educational training material in a wide variety of professional disciplines, in the construction industry. The paper has also discussed Computer-Aided-Learning and how multimedia has, and will in the future, figure as a major part in the development of CAL applications. The paper has also given examples of where multimedia has been used in the development of applications: - the BRIEFING application has used multimedia as a new form of disseminating information from a major research project; the BUILDING PATHOLOGY application has shown how VR and multimedia can be used to help learning in educational establishments, and finally the OSCON application has shown how multimedia can be used as an interface for complex database systems, particularly in the exchanging of construction project information over the Internet. The paper has shown how multimedia has played, and will continue to play a major part in the redesigning of communicating information between constructional professionals during a project, and that multimedia can be used as a valuable learning and training tool for construction professionals.

\section{References}

[1] Sanvido, VE, \& Medeiros, DJ, (1990), Applying Computer-Integrated Manufacturing concepts to Construction, Automation in Construction, June 1990, Vol.116, No.2, pp.365-379;

[2] Merchant, M, (1987), Computer-aided process planning - Integration and future trends, Proceedings of the $19^{\text {th }}$ International Seminar on Manufacturing Systems, I. Ham \& R. Wysk, eds, Centre International de Recherche en Production, June 1987;

[3] Gunasekaran, A, \& Reddy, R, (1999), Multimedia in Manufacturing - Special Issue of Computers in Industry, Vol.38, No.1 Jan.1999 Elsevier, also available at http://www.elsevier.n1/locate/compind;

[4] Weyrich, M, \& Drews, P, (1999), An Interactive Environment for Virtual Manufacturing: the Virtual Workbench, Computers in Industry, Vol.38, No.1, pp.5-15, Jan. 1999;

[5] Huang, GQ, \& Mak, KL, (1999) Design for manufacture and assembly on the Internet, Computers in Industry, Vol.38, No.1, pp.17-30, Jan. 1999;

[6] Crowder, RM, Hall, W, Heath, I, \& Wills, G, (1999) Integration of Manufacturing Information using Open Hypermedia, Computers in Industry, Vol.38, No.1, pp.31-42, Jan. 1999; 
[7] Vanegas, J, \& Baker, N, (1994) Multimedia in Civil Engineering, Civil Engineering, ASCE, Vol.64, No.5, pp.71-73;

[8] McCullouch, B, \& Patty, R, (1993), An INDOT lessons learned constructibility program and integrated multimedia system, JHRP;

[9] Saad, IMH, \& Hancher, DE, (1998), Multimedia for Construction Project Management: Project Navigator, Journal of Construction Engineering \& Management, Feb.1998, Vol.124, No.1, pp.82-89;

[10]El-Bibany, H, (1996), Multimedia Development Software: Object Oriented Interface-Based Simulation, Journal of Computing in Civil Engineering, Oct.1996, Vol.10, No.4, pp.295-299;

[11] Howard, R, (1997), Using multimedia to link expert's views and derive common conclusions, Automation in Construction, Vol.6, pp.3-9;

[12] Veeramani, D, Tserng, HP, \& Russell, JS, (1998) Computer-integrated collaborative design and operation in the construction industry, Automation in Construction, Vol.7, pp485-492;

[13] Papamicheal, K, LaPorta, J, \& Chauvet, H, (1997), Building design advisor: automated integration of multiple simulation tools, Automation in Construction, Vol.6, pp.341-352;

[14] Suppes, P, (1966), The Uses of Computers in Education, Scientific American, pp.215;

[15] Jackson et al, (1986), A Survey of Microcomputer use and Provision in Primary Schools, Journal of Computer Assisted Learning, Issue 2;

[16] Pratchett, Terry, (1991), Amazing Possibilities, Educational Computing and Technology;

[17] Wilson, Martyn, (1994), Educational and Training Technology International, Vol. 31;

[18]Ion, B., \& O’Donnell, F., (1996), Computer-Aided-Learning in Product Design Education, $3^{\text {rd }}$ National Conference on Product Design Education Proceedings, University of Central Lancashire, Preston, $15^{\text {th }}-16^{\text {th }}$ July, 1996 (also available at http://www.cad.strath.ac.uk/ frank/CAL/pde96.html);

[19]Barker, P, and King, T, (1993), Evaluating Interactive Multimedia Courseware - A Methodology, Computers in Education, Vol. 21 No. 4;

[20] Williams, H, \& Falconer, L, (1998), Differentiated Learning styles in on-line Learners - A case study in Asynchronous on-line distance learning for postgraduate health and safety professionals, The Bizarre Fruit Conference, BUHU Research Centre, The University of Salford, Nov. $18^{\text {th }} \& 19^{\text {th }} 1998$, pp.136-145;

[21] Tait, K, \& Hughes, IE, Some experiences in using a Computer Based Learning System as an aid to Self Teaching \& Self Assessment, Computers and Education Vol.8, No.3, pp.271-278;

[22] Barrett, P, and Stanley, C, (1998), Better Construction Briefing, Blackwells Publishing, Jun. 1999;

[23]Butters, J and Corke, C (1998), Supporting Innovation in Schools Project -SISP-, Information \& Visualisation Conference Proc., Southbank University, IEEE Computer Society, California, pp.99-104;

[24] Tait, K, (1995), An example of "Large Scale" Multimedia Courseware, Proceedings of the UK TOOLBOOK Users Conference, University of Bristol, November 1995, pp.130-139;

[25] Akpinar, Y, \& Hartley, JR, (1996), Designing Interactive Learning Environments, Journal of ComputerAssisted Learning, No.12, pp.133-146;

[26] Shelbourn, M., Aouad, G. \& Hoxley, M. (1998), An Integrated Virtual Reality and Case-Based Reasoning Model for Training in Building Pathology, Information \& Visualisation Conference Proceedings, Southbank University, IEEE Computer Society, Los Alamitos, California, p.44-49;

[27] Hollis, M \& Bright K, (1999), Surveying the Surveyors, in Structural Survey, Vol 17, issue 2, in print. 
[28] Brna, P, (1998), Collaborative Virtual Learning Environments for Concept Learning, International Journal of Continuing Engineering Education and Long Life Learning;

[29] Marshall, D., \& Worthing, D., (1995), The Construction of Houses, Estates Gazette;

[30] Oliveira, L. Retik, A. \& Watson, I. (1997), Intelligent Training Using Past Experiences in Virtual Reality: An Application for Scaffold Inspection. In, Proceedings of ARCOM97, Vol.2 pp.443-53;

[31] Marir, F., Aouad, G., Child, T., \& Brandon, P., (1998) OSCONCAD: a model based CAD system integrated with computer-related construction applications, ITcon the electronic journal, Vol 3, http://itcon.org;

[32] Ames, A, et al (1996), The VRML source book, John Wiley and sons, New York. 